\title{
Properties of intracellular magnetite crystals produced by Desulfovibrio magneticus strain RS-1
}

\author{
Mihály Pósfai ${ }^{a}$, Bruce M. Moskowitz ${ }^{\mathrm{b}}$, Balázs Arató ${ }^{\mathrm{a}}$, Dirk Schüler ${ }^{\mathrm{c}}$, \\ Christine Flies ${ }^{\mathrm{c}}$, Dennis A. Bazylinski ${ }^{\mathrm{d}}$, Richard B. Frankel ${ }^{\mathrm{e}}$ \\ a Department of Earth and Environmental Sciences, Pannon University, Veszprém, POB 158, H8200, Hungary \\ b Institute for Rock Magnetism, Department of Geology and Geophysics, University of Minnesota, 310 Pillsbury Dr. SE, \\ Minneapolis, MN 55455, USA \\ c Max Planck Institute for Marine Microbiology, Celsiusstr. 1, D-28359 Bremen, Germany \\ d Department of Biological Sciences, University of Nevada, 4505 Maryland Parkway, Las Vegas, NV 89154, USA \\ ' Department of Physics, California Polytechnic State University, San Luis Obispo, CA, USA
}

\begin{abstract}
Desulfovibrio magneticus strain RS-1 is an anaerobic sulfate-reducing bacterium. Cells form intracellular nanocrystals of magnetite but are only weakly magnetotactic. In order to understand the unusual magnetic response of this strain, we studied magnetite crystals within cells grown with fumarate and sulfate. Many cells grown under either condition did not form magnetic crystals while others contained only 1 to 18 small $(\sim 40 \mathrm{~nm})$ magnetite-containing magnetosomes. Bulk magnetic measurements of whole cells showed a superparamagnetic-like behavior, indicating that many of the magnetite crystals are too small to have a permanent magnetic moment at ambient temperature. The temperature of the Verwey transition is lower $(\sim 86 \mathrm{~K})$ than of magnetite from other magnetotactic strains, likely indicating partial oxidation of magnetite into maghemite. As a result of the small size and small number of magnetite magnetosomes, the magnetic moments of most cells grown anaerobically with fumarate or sulfate are insufficient for magnetotaxis.

In addition to intracellular magnetite, in some cultures another iron oxide, hematite, formed on the surfaces of cells. The hematite grains are embedded in an extracellular polymeric material, indicating that the crystals likely resulted from a biologicallyinduced mineralization process. Although the hematite particles appear to consist of aggregations of many small (5 to $10 \mathrm{~nm}$ ) grains, the grains have a consensus orientation and thus the whole particle diffracts as a single crystal. The aligned arrangement of nanoparticles within larger clusters may reflect either a templated nucleation of hematite crystallites in an extracellular organic matrix, or result from a self-assembling process during the crystallization of hematite from ferric gels or ferrihydrite.
\end{abstract}

Keywords: Desulfovibrio magneticus; magnetite; hematite; magnetic properties; magnetotaxis

\section{Introduction}

Biogenic processes are important in the formation of iron oxides in many environments. Both the biologically- 
controlled mineralization (BCM) of intracellular magnetite [1-3] and the biologically-induced mineralization (BIM) of magnetite, goethite, lepidocrocite, ferrihydrite, and other iron oxides [4-7] have been extensively studied. Magnetite crystals produced through BCM attracted great interest as a potential biomarker both in terrestrial and extraterrestrial materials $[8,9]$. An intriguing problem is how magnetotactic bacteria control the growth of magnetite crystals that have species-specific sizes and morphologies. With regard to BIM iron oxides, it is important to understand the nucleation processes of inorganic crystals on biological surfaces or within organic matrices $[10,11]$. We wished to obtain more insight into $\mathrm{BCM}$ and BIM iron oxide-forming processes by studying biomineralization in Desulfovibrio magneticus strain RS1 that appears to produce both intracellular magnetite and extracellular hematite, as well as extracellular iron sulfides.

D. magneticus strain RS-1 was first isolated from freshwater sediments by Sakaguchi et al. [12], and described as an obligately anaerobic, dissimilatory sulfate-reducing bacterium that produces intracellular magnetite and extracellular iron sulfides. However, in contrast to other magnetite-bearing, magnetotactic bacteria, the response of cells of strain RS-1 to external magnetic fields was so weak that cells could not be harvested using magnetic collection methods [13]. Phylogenetic analysis based on the partial 16S rDNA sequence showed that strain RS-1 is a member of the genus Desulfovibrio in the $\delta$-Proteobacteria [14]. Based on a detailed study of the physiology and biochemical characteristics of RS-1, a novel species, D. magneticus, was proposed [15].

D. magneticus is unique among magnetotactic bacteria both in terms of its weak magnetotactic response and phylogenetic position. The only other magnetotactic microorganism currently associated with the $\delta$-Proteobacteria is the multicellular magnetotacic prokaryote (MMP; [16]); however, this organism synthesizes intracellular iron sulfides, including greigite, $\mathrm{Fe}_{3} \mathrm{~S}_{4}$ [17-20], and mackinawite, FeS [19,20], but not magnetite. Biomineralization by D. magneticus has significant geological implications in that this species produces magnetite in a sulfidic, reducing environment.

We studied the magnetosomes in D. magneticus in order to understand why the magnetic response of cells of strain RS-1 is so poor compared to that of other magnetotactic bacteria. We used bulk magnetic methods and transmission electron microscopy (TEM) imaging for characterizing the magnetosomes. While looking for intracellular iron oxide crystals, we found hematite $\left(\mathrm{Fe}_{2} \mathrm{O}_{3}\right)$ grains attached to the surfaces of cells in one of the cultures, and studied them using high-resolution TEM (HRTEM) and electron diffraction.

\section{Experimental details}

D. magneticus RS-1 (DSM No. 13731) was obtained from the DSMZ type culture collection (Braunschweig, Germany). Two different media were used for cultivation. The sulfate-free medium (medium No. 896 from DSMZ) contained pyruvate and fumarate as electron donor and acceptor, respectively, and was prepared anaerobically according to the method of Widdel and Bak [21]. Alternatively, a defined, freshwater growth medium for sulfate-reducing bacteria was used containing $5 \mathrm{mM}$ pyruvate as electron donor as described by Widdel and Bak [21]. Cells were either cultivated in $20 \mathrm{ml}$ tubes containing $10 \mathrm{ml}$ growth medium or $155 \mathrm{ml}$ serum vials containing $55 \mathrm{ml}$ of growth medium with $\mathrm{O}_{2}$-free $\mathrm{N}_{2}$ in the headspace. The tubes were sealed by butyl rubber stoppers. Incubation was at room temperature without agitation.

Cells were harvested from cultures by centrifugation at $10,000 \times g$ for $20 \mathrm{~min}$ at $4{ }^{\circ} \mathrm{C}$ under $\mathrm{N}_{2}$. The supernate was discarded and the pellets (containing cells and precipitates) were frozen at $-70{ }^{\circ} \mathrm{C}$ and then freeze-dried.

Samples were prepared for magnetic measurements by lightly packing freeze-dried cells of $D$. magneticus grown on fumarate or sulfate in separate gelcaps. Roomtemperature magnetic hysteresis loops and remanence curves were measured using a Princeton Measurements Vibrating Sample Magnetometer in a maximum field of $1.7 \mathrm{~T}$. Low-temperature remanent magnetization and AC susceptibility were measured using a Quantum Design Magnetic Property Measurement System across the temperature range of 20 to $300 \mathrm{~K}$. Saturation remanence acquired in a $2.5 \mathrm{~T}$ field at $20 \mathrm{~K}$ was measured on warming from $20 \mathrm{~K}$ to $300 \mathrm{~K}$ following two different magnetic field pre-treatments. The first pre-treatment was produced by cooling the sample down from $300 \mathrm{~K}$ to $20 \mathrm{~K}$ in a zero magnetic field (zero field cooled, ZFC), whereas the second pre-treatment was produced by cooling the sample to $20 \mathrm{~K}$ in a $2.5 \mathrm{~T}$ field (field cooled, FC). The delta-delta ratio given by $\delta \mathrm{FC} /$ $\delta \mathrm{ZFC}$, with $\delta=(J(80 \mathrm{~K})-J(150 \mathrm{~K})) / J(80 \mathrm{~K})$ was calculated from the FC and ZFC data [22,23], and is a measure of the amount of remanence lost upon warming through the Verwey transition. A room temperature saturation remanence (RTSIRM) was also measured during temperature cycling from $300 \mathrm{~K} \rightarrow 20 \mathrm{~K} \rightarrow 300 \mathrm{~K}$. In-phase and out-of-phase susceptibilities were measured in an AC field with peak amplitude of $0.3 \mathrm{mT}$ field for 7 different frequencies $(1,3,10,30,100,300$, and 
$1000 \mathrm{~Hz}$ ) at $5 \mathrm{~K}$ intervals from $20 \mathrm{~K}$ to $300 \mathrm{~K}$. However, measurement noise increases with frequency, so the susceptibility data for frequencies greater than $100 \mathrm{~Hz}$ were not included.

Samples for electron microscopy were prepared from young (1 day incubation) or stationary cultures ( 2 weeks incubation) of $D$. magneticus grown in both media. Cells were deposited on $\mathrm{Cu}$ and Ni TEM grids covered by a carbon-coated Formvar film. Electron microscopy was performed using a Philips CM20 instrument operated at $200 \mathrm{kV}$ accelerating voltage. The compositions of mineral grains were determined with an attached Noran Voyager detector using energy-dispersive X-ray spectrometry (EDS). HRTEM images were obtained using a 300-kV JEOL 3010 and a 400-kV JEOL $4000 \mathrm{EX}$ microscope. For image processing (filtering of HRTEM images and obtaining Fourier transforms) we used Digital Micrograph software. We obtained size distributions by fitting ellipses to the outlines of crystals, and then using the average of the short and long axes of the best-fitting ellipse as the diameter of the crystal $[24,25]$.

\section{Results}

\subsection{Magnetic properties of RS-1 cultures}

Hysteresis loops for the fumarate-grown cells (RS1$\mathrm{AF})$ and sulfate-grown cells (RS1-BS) have "normal" shapes, with no evidence of wasp-waisted, pot-bellied, or other anomalous shapes [26], suggesting a single magnetic component is the main source of coercivity. Remanence acquisition curves at room temperature for RS1-AF and RS1-BS are shown in Fig. 1. Both samples show similar behavior and approach saturation by $0.1 \mathrm{~T}$, indicating ferrimagnetic minerals like magnetite or maghemite rather than antiferromagnetic minerals like hematite or goethite contributing to the remanence. Saturation magnetization $\left(M_{\mathrm{S}}\right)$ values obtained from the hysteresis loops are $0.0176 \mathrm{~A} \mathrm{~m}^{2} / \mathrm{kg}$ (RS1-AF) and $0.0363 \mathrm{~A} \mathrm{~m}^{2} / \mathrm{kg}$ (RS1-BS). Using a $M_{\mathrm{s}}$ value of $92.4 \mathrm{~A}$ $\mathrm{m}^{2} / \mathrm{kg}$ value for pure magnetite [27], the magnetite content by mass of cells is $0.02 \%$ (RS1-AF) and $0.04 \%$ (RS1-BS). The magnetite content of cells of $D$. magneticus is significantly lower than observed in other strains of magnetotactic bacteria (e.g., Magnetospirillum magnetotacticum and strain MV-1), which typically have magnetite contents ranging from $0.5 \%$ to $2 \%[22,28]$. The magnetization ratios of saturation remanence $\left(M_{\mathrm{r}}\right)$ to saturation magnetization $\left(M_{\mathrm{r}} / M_{\mathrm{s}}\right)$ for RS1-AF and RS1-BS are 0.440 and 0.340 , respectively. The theoretical $M_{\mathrm{r}} / M_{\mathrm{S}}$ value for a randomly oriented

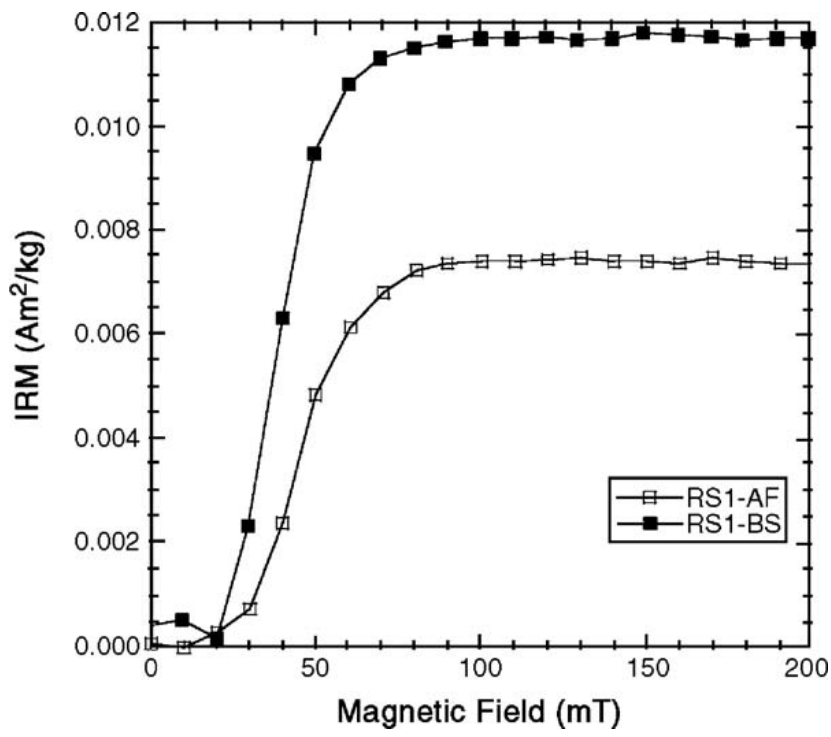

Fig. 1. Isothermal remanent magnetization (IRM) acquisition curves at room temperature for D. magneticus fumarate grown cells (RS1-AF) and sulfate grown cells (RS1-BS).

assemblage of non-interacting single domain particles with uniaxial anisotropy is 0.5 . Remanence ratios ranging from 0.45 to 0.5 are commonly found in other strains of magnetotactic bacteria [22,28]. Reduced values measured for cells of D. magneticus, and particularly in sulfate-grown cells, is likely the result of a significant fraction of superparamagnetic (SPM) particles $(<30 \mathrm{~nm})$ present within the cells. Finally, room-temperature values for the coercivity of remanence $\left(H_{\mathrm{cr}}\right)$ are $46.7 \mathrm{mT}$ (RS1-AF) and $35.8 \mathrm{mT}$ (RS1BS) and are within the range of $H_{\mathrm{cr}}$ values observed for other strains of magnetotactic bacteria.

Both samples show very similar behavior in their remanence and susceptibility trends with temperature between $20 \mathrm{~K}$ and $300 \mathrm{~K}$; therefore only results for RS1$\mathrm{BS}$ are shown. Low-temperature warming curves for FC and ZFC remanent magnetizations are shown in Fig. 2. The remanence loss at $\sim 86 \mathrm{~K}$ for both samples and the bifurcation of the FC-ZFC curves below $86 \mathrm{~K}$ is associated with the Verwey transition $\left(T_{\mathrm{v}}\right)$ in magnetite (pure stoichiometric magnetite, $T_{\mathrm{v}}=121 \mathrm{~K}$ ), and confirms the presence of magnetite in both samples [22]. The bifurcated FC-ZFC curves below $T_{\mathrm{v}}$ with FC remanence greater than the $\mathrm{ZFC}$ remanence also indicate that most of the magnetite particles are in the stable SD size range $(\sim 30-100 \mathrm{~nm})$. Delta-delta ratios are 3.0 and 1.83 for RS1-AF and RS1-BS, respectively. However, the original expression for the delta-ratio used by Moskowitz et al. [22] assumes that the Verwey transition is at a temperature greater than $100 \mathrm{~K}$. In our case, most of the remanence drop due to the Verwey transition 


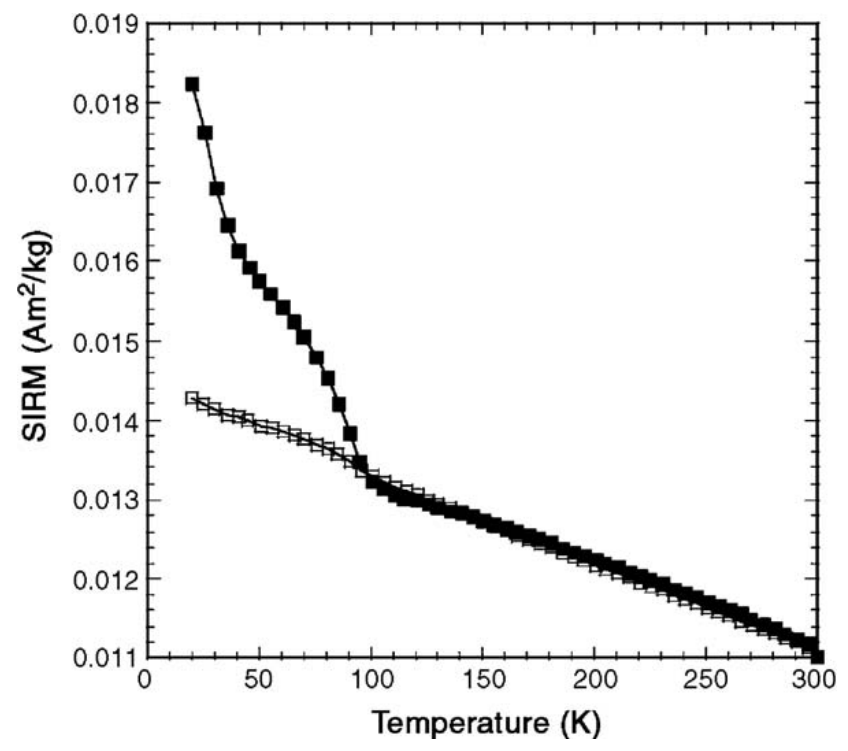

Fig. 2. Low temperature demagnetization of a saturation isothermal remanent magnetization (SIRM) on warming after field cooled (solid symbols) and zero-field cooled (open symbols) pre-treatments for RS1-BS. SIRM was acquired at $20 \mathrm{~K}$ in a magnetic field of $2.5 \mathrm{~T}$.

occurs below $100 \mathrm{~K}$, making the original delta ratios a poor measure of the remanence changes associated with $T_{\mathrm{v}}$. Re-defining the temperature range over which the delta ratios are calculated from $80-150 \mathrm{~K}$ to $50-120 \mathrm{~K}$ to account for the low $T_{\mathrm{v}}=85 \mathrm{~K}$, increases the deltadelta ratios to 5.54 and 2.74 for RS-1AF and RS-1BS, respectively. Delta-delta ratios greater than 2.0 are characteristic of intact chains of SD magnetite magnetosomes [22,29-31].

The Verwey transition temperatures for both samples of cells of D. magneticus are significantly lower than observed for fresh cells of other strains of magnetotactic bacteria which have transition temperatures near 100$115 \mathrm{~K}[22,31]$. In contrast, a depressed Verwey transition temperature was observed for aged cells of strain MV-1 compared to the fresh equivalent [23]. The suppressed nature of the transition is consistent with the early stages of oxidation in submicron magnetite $[32,33]$ and suggests partial oxidation of the magnetosomes has taken place in both samples of $D$. magneticus.

Cooling $(300 \mathrm{~K} \rightarrow 5 \mathrm{~K})$ and warming $(5 \mathrm{~K} \rightarrow 300 \mathrm{~K})$ curves for a room-temperature SIRM are shown in Fig. 3. Both samples show a small (6-8\%) but steady increase in magnetization with decreasing temperature until levelling off at about $50 \mathrm{~K}$. Warming back across the Verwey transition to $300 \mathrm{~K}$ results in a near perfect memory ( $>98 \%$ ) of the initial room-temperature SIRM. There is little evidence of a Verwey-like transition or the Morin transition $(T=260 \mathrm{~K})$ associated with hematite in the RTSIRM curves.
The temperature dependence of in-phase $\left(\chi^{\prime}\right)$ and quadrature $\left(\chi^{\prime \prime}\right)$ susceptibility for freeze-dried cells of $D$. magneticus is displayed in Fig. 4. Cells of D. magneticus display a general monotonic increase for both the inphase and quadrature components of susceptibility with increasing temperature, until it reaches a plateau around $200 \mathrm{~K}$. The quadrature susceptibility is less than $10 \%$ of the in-phase susceptibility. Again, this is atypical behavior when compared to other strains of magnetotactic bacteria, which exhibit characteristic maxima followed by a sharp drop at the Verwey transition around $100 \mathrm{~K}$ [34]. The in-phase susceptibility is also frequency dependent, and the frequency dependence is observed at all temperatures. The frequency dependent parameter $\chi_{\mathrm{FD}}$ (e.g., [35]) at room temperature is $6.0 \%$ for RS1-BS and $4.5 \%$ for RS1-AF, and reaches a maximum of $8.3 \%$ at $100 \mathrm{~K}$ (for RS1-BS). The maximum in $\chi_{\mathrm{FD}}$ at $100 \mathrm{~K}$ coincides with the change in slope in $\chi^{\prime \prime}-T$. This indicates a median blocking temperature of $100 \mathrm{~K}$, but it may also correspond to additional blocking due to the increase in the intrinsic magnetocrystalline anisotropy in monoclinic magnetite below the Verwey transition. The nearly flat but non-zero values of the $\chi^{\prime \prime}-T$ curve between 100 and $300 \mathrm{~K}$ suggest that a fraction of the particle volumes distribution have blocking temperatures above $300 \mathrm{~K}$, where presumably the $\chi^{\prime \prime}-T$ would reach a maximum before falling to zero. Both the temperature and frequency behaviour are hallmarks of superparamagnetic nanoparticles with blocking temperatures extending up to room temperature

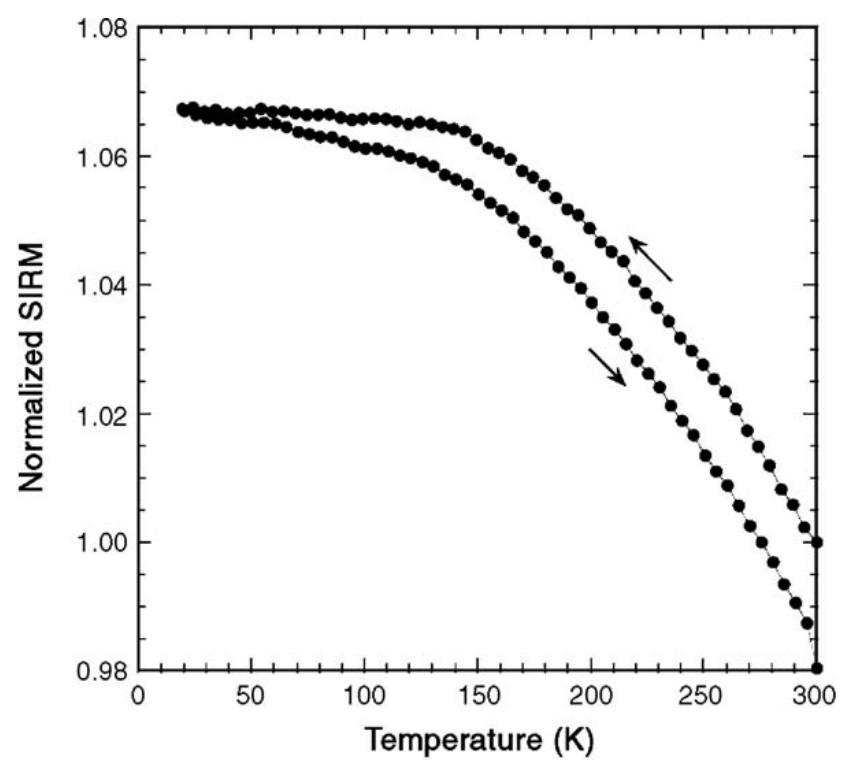

Fig. 3. Normalized room-temperature isothermal remanent magnetization (RTSIRM) for RS1-BS during zero-field cooling to $20 \mathrm{~K}$ and zerofield warming back to $300 \mathrm{~K}$. SIRM was acquired at $300 \mathrm{~K}$ in a magnetic field of $2.5 \mathrm{~T}$. 

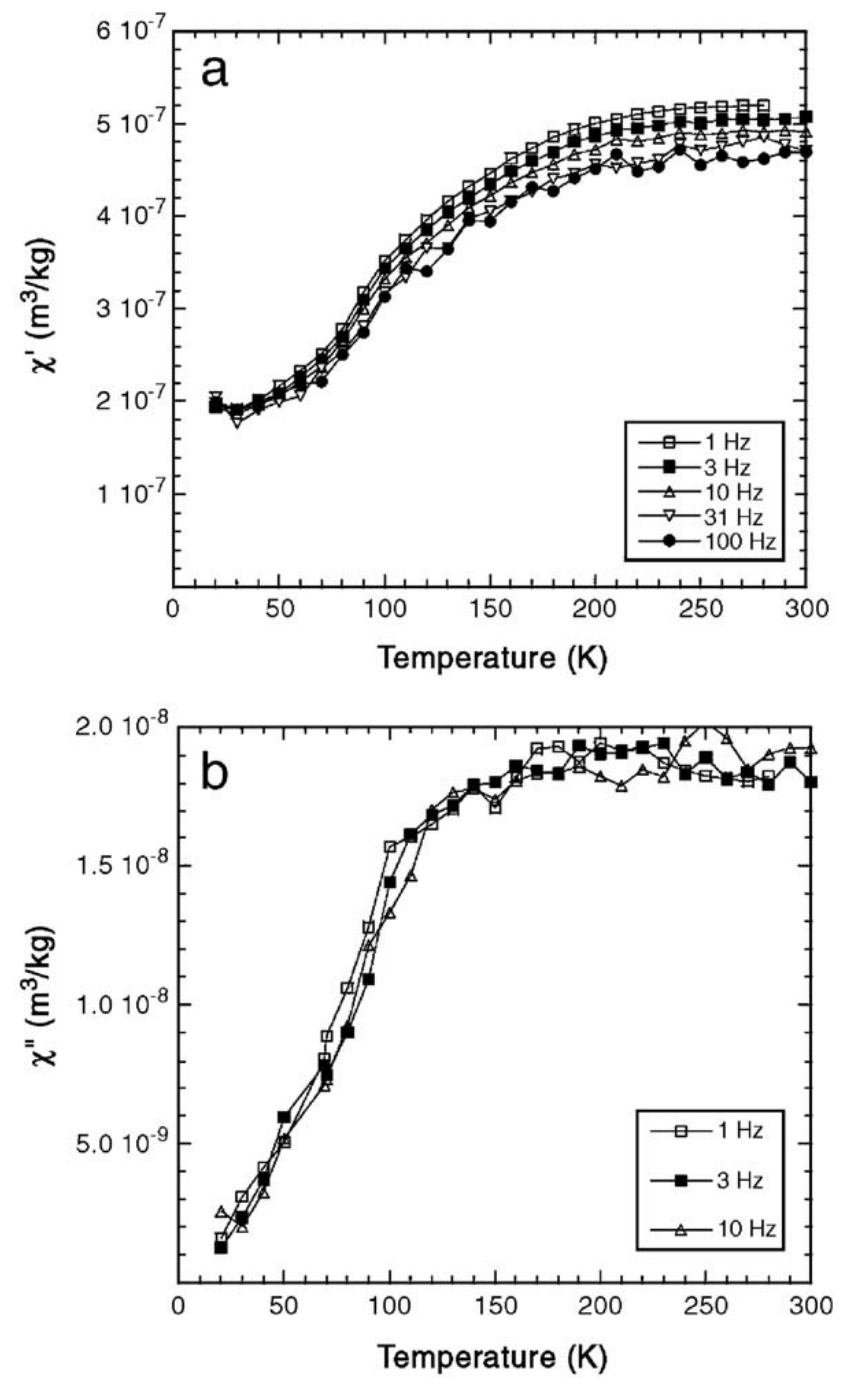

Fig. 4. In-phase susceptibility (a) and quadrature susceptibility (b) as a function of temperature and frequency for sample RS1-BS.

and above, and a particle size distribution that extends down from stable SD sizes into the SPM size range. This is also consistent with the hysteresis data at room temperature that shows both finite values of coercivity and reduced values of $M_{\mathrm{r}} / M_{\mathrm{S}}$ indicating a mixture of SPM and SD particles.

The thermal and frequency dependent susceptibility variations for $D$. magneticus are similar in form to results obtained on biogenic magnetites produced extracellularly by dissimilatory iron-reducing bacteria like Geobacter metallireducens [34]. These organisms produce magnetite crystals with lognormal particle size distributions that extend well into the SPM size range for magnetite but with only a small fraction of stable SD grains [36]. Although the $\chi^{\prime}-T$ behavior is similar, the low-temperature remanence curves are completely different between these two microorganisms. Whereas magnetite produced by Geobacter shows an initial rapid decrease in ZFC remanence on warming [22,36], magnetite particles produced by D. magneticus display a more gradual decrease in remanence on warming (Fig. 2 ). This contrast is a reflection of the underlying differences in the particle size distributions. Geobacter produces a broad particle size distribution with significant fraction of SPM particles with small particle volumes exhibiting very low blocking temperatures $(<50 \mathrm{~K})$. In contrast, cells of D. magneticus do not produce such fine SPM particles. Instead, the SPM particles are coarser in size and limited to the size range near the stable SD threshold size at room temperature $(\sim 30 \mathrm{~nm})$.

\subsection{Intracellular magnetite magnetosomes by TEM}

Cells of D. magneticus grown in either medium contained at most 18 magnetite crystals, but the majority were magnetite-free (Fig. 5a). The magnetite magnetosomes are small $(\sim 40 \mathrm{~nm})$ and have elongated, irregular shapes (Fig. 5b). In contrast to most magnetotactic strains that produce magnetite crystals with asymmetric, negatively-skewed size distributions [24,25], magnetite crystals biomineralized by $D$. magneticus have a symmetric, Gaussian distribution (Fig. 5c). Similar size distributions were observed for intracellular greigite in the multicellular magnetotactic prokaryote, MMP [37] and in a magnetite-producing, uncultured bacterium [25]. In all these cases the normal crystal size distribution was associated with irregular crystal morphologies. Although the habits of the crystals appear irregular, they share some interesting morphological features. Many crystals appear to consist of two distinct parts: a base that has a triangular shape in the two-dimensional projection and an elongated, pointed second part (Fig. 5e). The straight edges of the "base" triangles are parallel to (111)-type planes. In contrast to most types of bacterial magnetite, the crystals are elongated along [100], not [111].

Magnetite nanocrystals produced by $D$. magneticus appear to be free of structural defects (Fig. 5e); in a selected-area electron diffraction (SAED) pattern from a single magnetite crystal, faint additional reflections appear that may indicate the partial oxidation of magnetite into maghemite (Fig. 5d).

\subsection{Extracellular hematite}

Extracellular polymers are associated with the cells of D. magneticus grown in either medium. EDS analyses show that the web-like substance on the surfaces of cells consists either of carbonaceous material only (Fig. 6a), or of carbonaceous material with metal-containing 

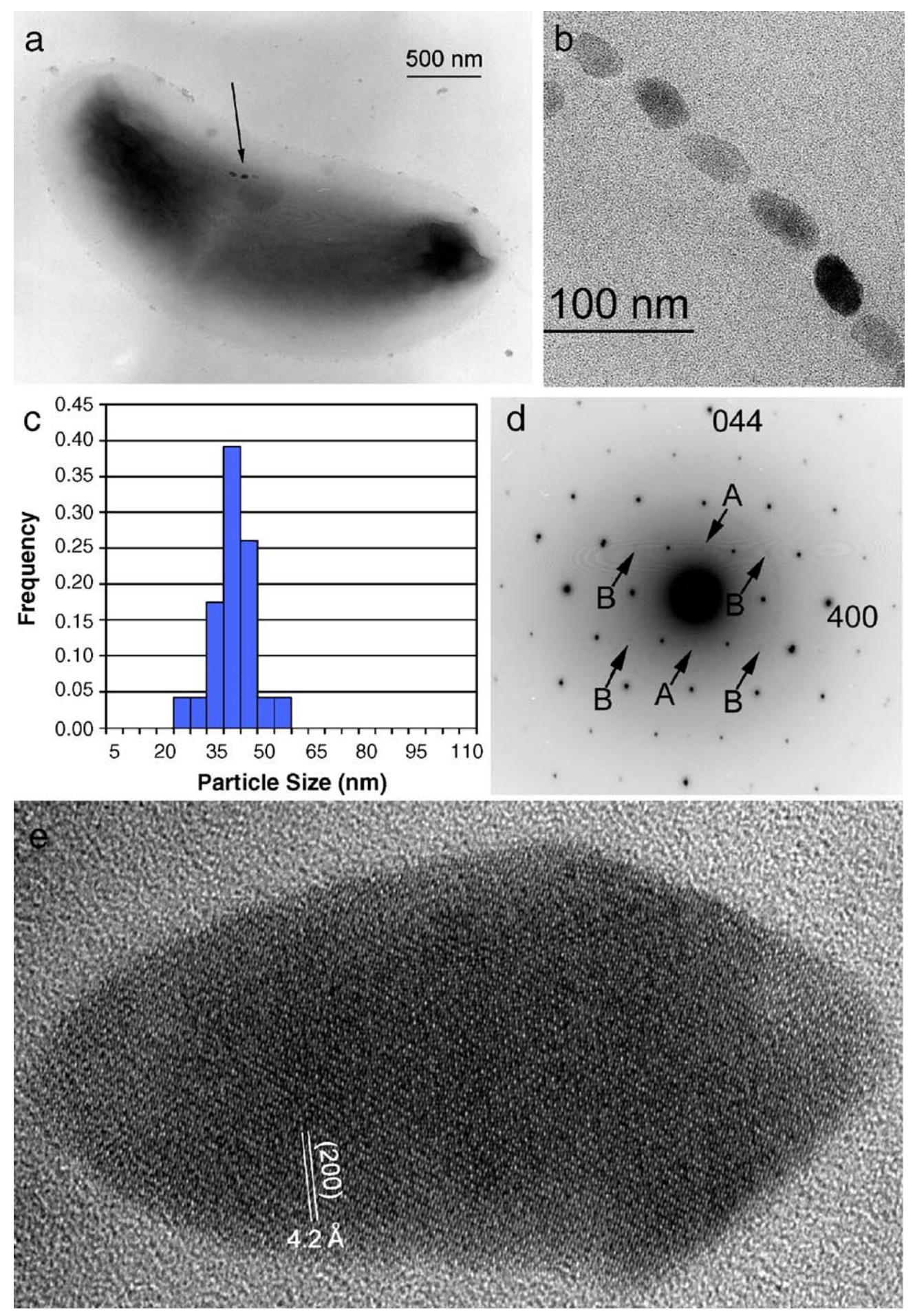

Fig. 5. (a) Three magnetite crystals (arrowed) in a cell of D. magneticus. (b) A chain of irregularly-shaped magnetite magnetosomes. (c) Crystal size distribution of intracellular magnetite crystals (23 particles were measured). (d) Selected-area electron diffraction pattern and (e) corresponding highresolution image of a magnetite magnetosome, viewed along [110]. The weak, arrowed reflections in (d) are forbidden by the magnetite structure, and their presence indicates that the crystal is transforming into maghemite (A and B mark 011- and 211-type reflections, respectively, indexed according to the cubic $\mathrm{P} 4{ }_{1} 32$ space group of maghemite).

deposits. In a fumarate-grown culture, Fe oxide particles commonly occur on the extracellular polymers (Fig. 6b). The rounded, fairly uniformly-sized particles have a grainy appearance and seem to consist of many smaller crystallites (Fig. 6c). Nevertheless, the Fe oxide particles produce single crystal-like SAED patterns that indicate an almost identical orientation of the individual grains ("nanograins") within each larger particle (Fig. 6d). The $\mathrm{d}$-spacings and angles in the SAED patterns are consistent with the structure of hematite. 

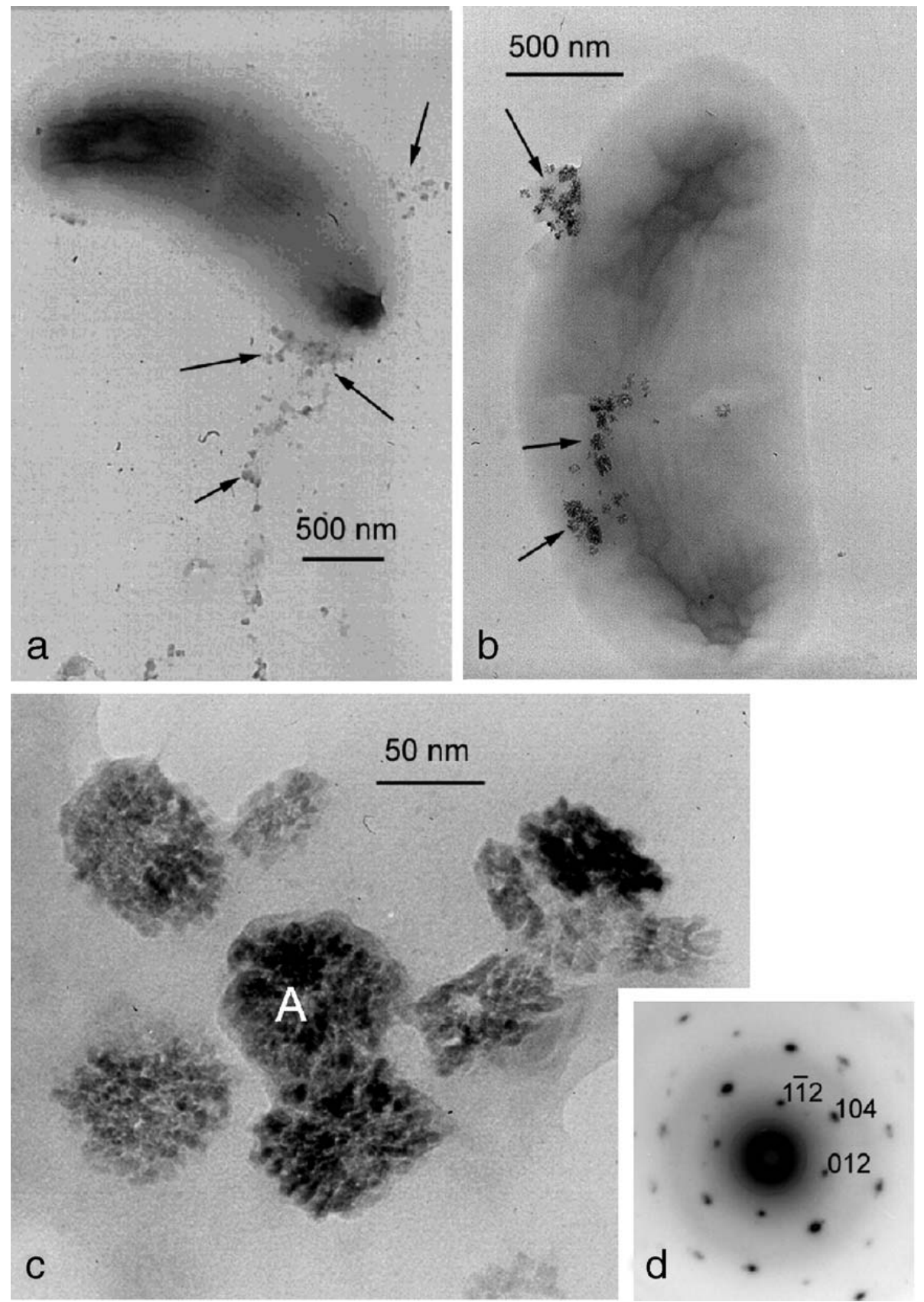

Fig. 6. (a) Extracellular polymeric material (marked by arrows) attached to a cell of D. magneticus. (b) Hematite particles (arrowed) embedded in extracellular material. (c) Grainy appearance of hematite particles suggests that they consist of smaller crystallites. (d) Selected-area electron diffraction pattern obtained from the particle marked $\mathrm{A}$ in (c); the pattern indicates that the particle diffracts as a single crystal.

HRTEM images confirm that the nanograins have a consensus orientation within each hematite particle (Fig. 7). In some nanograins in Fig. $7 \mathrm{~b}$ rows of dots along the hematite $(-210)$ and $(-120)$ planes are spaced at $\sim 2.9 \AA$ intervals and thus can be regarded as representing $\left[\mathrm{FeO}_{6}\right]$ octahedra. Similar rows of dots in the same orientation appear in other nanograins, whereas in the spaces between the grains only fringes or no structural detail can be observed. The contrast in the TEM is not uniform; some grains appear darker than others (Fig. 7a). This effect is probably caused by slight orientational differences, although the variable size and thus thickness of nanograins may also contribute to contrast variation.

The size distribution of hematite particles is basically symmetric, with a maximum at $\sim 70 \mathrm{~nm}$ (Fig. 8a). A few large particles $(>110 \mathrm{~nm})$ occur that may have formed by the aggregation of the original particles. The relatively broad shape factor distribution (Fig. 8b) indicates the irregular shapes of hematite particles; although most grains are only slightly elongated, 


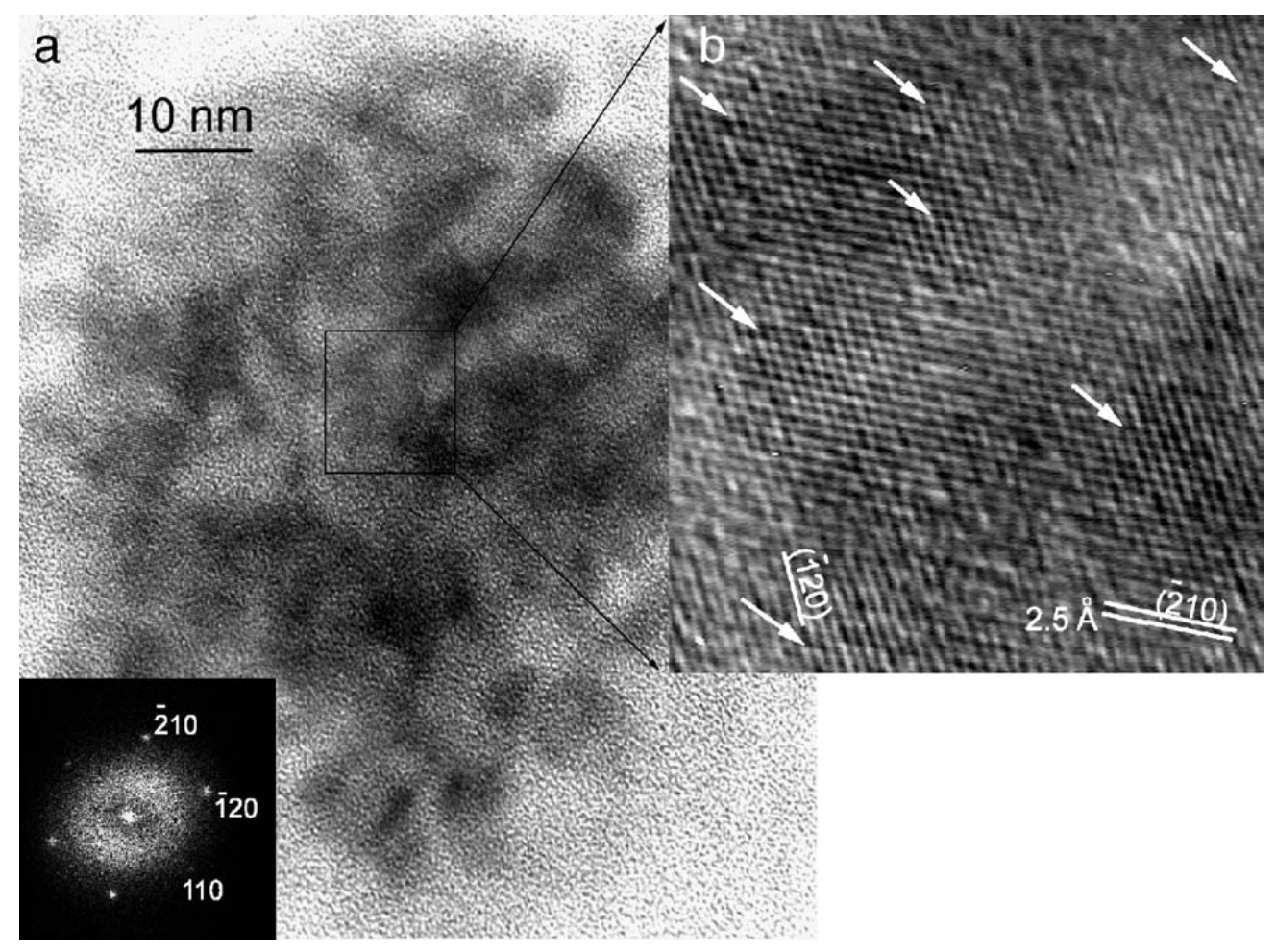

Fig. 7. (a) High-resolution TEM image of a hematite particle oriented with [001] parallel to the electron beam (as indicated by the Fourier transform in the inset), and (b) rotationally filtered image of the area marked in (a). Note the uniformly oriented, ordered islands ("nanograins," marked by arrows) in (b).

particles having higher aspect ratios (lower shape factor values) also occur.

\section{Discussion}

The weak magnetotactic response of cells of $D$. magneticus is understandable in light of the bulk magnetic measurements and TEM observations of magnetite magnetosomes. Only a small fraction of cells contain magnetite. Frequency-dependent susceptibility and low-temperature susceptibility data indicate the presence of superparamagnetic particles. Particle sizes measured in TEM images confirm that most magnetite crystals in cells of D. magneticus are only slightly larger than $30 \mathrm{~nm}$, close to the theoretical lower size limit of permanent single magnetic domains in magnetite at room temperature [27]. In addition, the magnetosomes often are not organized in well-structured chains; there are large gaps between magnetite crystals. In other magnetotactic strains even small $(<30 \mathrm{~nm})$ and larger $(>120 \mathrm{~nm})$ magnetite crystals are single magnetic domains because of magnetic interactions among crystals in well-organized chains [38-40]; such interactions cannot occur in D. magneticus. Since the cells contain very few magnetite crystals that do not form ordered chains, the magnetic moments of most individual cells are insufficient to orient the cells along the geomagnetic field lines. In fact, it may not be proper to call D. magneticus a magnetotactic bacterium, even though it has been described as such. Apparently, the magnetite crystals are not used by the bacteria for magnetotaxis; thus, the reason for intracellular magnetite formation is unclear. Iron-bearing inclusions in other, non-magnetotactic microorganisms have been described by Vainshtein et al. [41] and Glasauer et al. [42]. These authors speculated that iron oxide formation is either a means for storing iron, or serves a detoxification purpose. In either case, however, it is intriguing that the morphologies of the crystals seem to be under genetic control. Similar, pointed magnetite crystals occur in many magnetotactic strains [43-45]. In addition to the control over morphology, the orientations of magnetite crystals appear to be regulated, with [100] set parallel to the chain of magnetosomes and the axis of the cell.

The magnetic results show an asymmetry in the detection of the Verwey transition between SIRM warming (FC and ZFC) and cooling (RTSIRM) experiments. The remanence expression of the transition is enhanced for an FC experiment as the transition temperature is approached from low temperatures but completely suppressed for an RTSIRM experiment when the transition temperature is approached from high temperatures. A possible explanation for this asymmetric behavior is in the observed crystallographic 

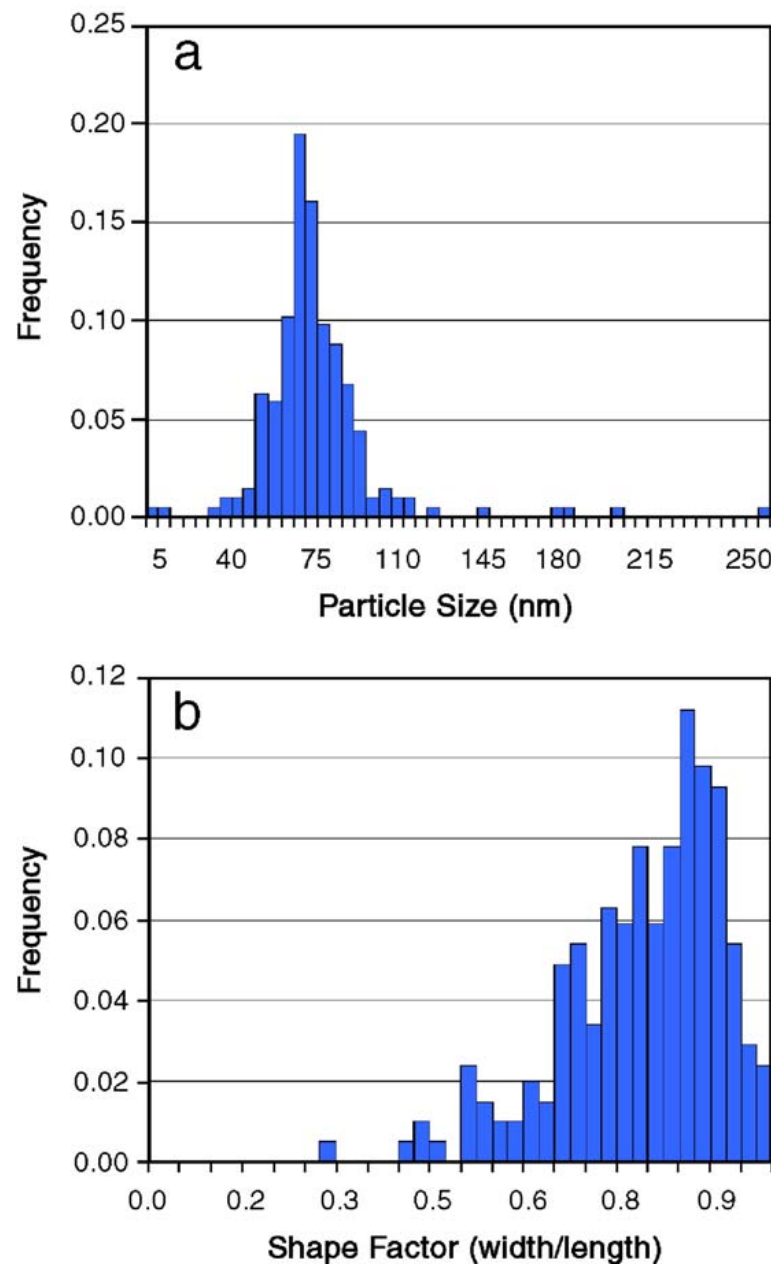

Fig. 8. (a) Size and (b) shape factor (width/length) distribution of extracellular hematite particles. A total of 205 particles were measured.

orientations of the magnetosomes in D. magneticus and the magnetic response of remanence cycling through the Verwey transition. The TEM results show that the magnetosome particles are elongated along the [100] directions instead of the [111] magnetic easy directions as observed in other species of magnetotactic bacteria. At the Verwey transition, there is a cubic to monoclinic structural phase transition, where one of the original [100] cubic directions becomes the new monoclinic $c$ axis (also the magnetic easy axis). Strong magnetic fields can force the monoclinic $c$-axes to pick a particular [100] direction closest to the applied field direction during field cooling through the transition. This is the basis of the delta-delta parameter. For the magnetosome particles produced by D. magneticus, the magnetization for each individual magnetosome is most likely aligned along the axis of elongation, which is a [100] direction. Upon cooling an RTSIRM through the Verwey transition, there is little or no magnetization rotation away from the [100] direction towards the low- temperature monoclinic $c$-axes because in this case the original [100] remanence direction becomes the new monoclinic $c$-axis. In contrast, field cooling through $T_{\mathrm{V}}$ would still partially align the monoclinic $c$-axes along another [100] direction closest to the field direction and maximize the amount of remanence loss on subsequent warming back through the Verwey transition. This might also explain the observation of elevated deltadelta ratios in D. magneticus, which has magnetomes that are not well organized into chains. The [100] alignment reduces the ZFC response but not the FC response, resulting in an anomalously high delta-delta ratio. Finally, another contributing factor to the asymmetric remanence behavior and elevated delta-delta ratios is the partial oxidation of the magnetosomes which could also drive the asymmetry associated with remanences acquired in the cubic phase at high temperature and in the monoclinic phase at low temperature [23].

The extracellular formation of hematite is interesting, even though we observed hematite in one culture only, and do not know the cause of its formation. Since iron in hematite is in a fully oxidized state, whereas the anaerobic environment in which cells of D. magneticus were cultured was reducing, it appears that the solution chemistry within the extracellular polymeric material differs from that of the culture medium. It is unlikely that the formation of hematite is an artifact; the samples were never exposed to oxidizing conditions during culturing. We note that the samples used for magnetic measurements did not contain hematite. For a better understanding of the formation and significance of hematite, we are designing new experiments. Although this is planned for the future, in the present study we give a preliminary account of our observations on hematite.

Whereas most of the common iron oxide and hydroxide minerals are known to be readily produced by biomineralization $[46,11]$, there are few reports of the biogenic formation of hematite [47]. In addition to other iron minerals, aggregations of randomly oriented, 1 to 50 -nm hematite nanocrystals were extracted from grass samples [5]. These nanocrystals formed the inorganic cores of phytoferritin, and thus can be regarded as products resulting from BCM processes. Poorly ordered hematite crystals were found associated with bacterial cells and their formation attributed to BIM processes $[48,49]$. Hematite was also identified as a minor phase in the mineral cores of physiological ferritin in horse spleen, human liver and brain [50]. The biogenic hematite particles described in this study are unique in that they consist of crystallographically aligned nanograins. 
The extracellular polymer matrix may play a role in the oriented arrangement of hematite crystallites. Organic surfaces or matrices template the oriented nucleation and growth of nanocrystals in biomimetic systems. Examples include the oriented arrays of magnetite nanocrystals on polyvinyl alcohol surfaces [51], assemblies of goethite nanocrystals formed on polysaccharide alginic acid fibrils [52], and spectacular pseudo-octahedral calcite "single" crystals composed of highly aligned nanocrystals that formed in a polyacrylamide hydrogel network [53]. Oriented arrays of magnetite nanocrystals occur in plants and produce single crystal-like SAED patterns [3]. Although possible, at present we do not know whether the extracellular polymers associated with cells of $D$. magneticus have a templating role in hematite nucleation.

Alternatively, the ordered alignment of hematite nanograins on cells of $D$. magneticus can be explained by a self-assembling process. Hematite is known to form by the transformation of ferric gels [54] or ferrihydrite [55] through dehydration and structural rearrangement. Although the complete transformation of ferrihydrite to hematite requires temperatures $>80{ }^{\circ} \mathrm{C}$ [55], Janney et al. [56] found hematite associated with ferrihydrite synthesized at room temperature. Ferrihydrite nanocrystals produced by iron-oxidizing bacteria were shown to aggregate and rotate so the individual crystallites shared a common orientation [7]. In general, drying can mediate self-assembly of nanoparticles [57], and crystallographically coherent boundaries are energetically favorable over random orientations [10]. In the case of the hematite formed on cells of D. magneticus, it is possible that the role of the extracellular organic material in the mineralization process is limited to providing nucleation sites for ferric oxides or oxyhydroxides, and the common crystallographic orientation of the nanograins is a consequence of their self-alignment during the transformation of initial precipitates into hematite.

Both intracellular magnetite and extracelllular hematite particles produced by cells of $D$. magneticus exhibit Gaussian CSDs (Figs. 5 and 8), suggesting a random crystal growth process. Similar CSDs are characteristic for intracellular greigite from cells of a multicellular magnetotactic prokaryote (MMP; [37]) and magnetite crystals from an uncultured, magnetotactic bacterium [25]. Interestingly, greigite, magnetite, and hematite particles that exhibit symmetric CSDs also have irregular crystal morphologies and disordered or semiordered spatial distributions within or outside cells. In contrast, magnetite crystals from several other magnetotactic strains typically have asymmetric, negatively skewed CSDs $[24,25]$; these crystals have well-defined morphologies and tend to remain in ordered chains within dehydrated cells on the TEM grids. It appears that the biogenic controls over crystal size, morphology, and chain formation are related in magnetotactic bacteria.

\section{Acknowledgements}

This is IRM contribution 0405. The IRM is supported by the Instrumentation and Facilities program, Earth Science Division, National Science Foundation. DAB is supported by US National Science Foundation grant EAR-0311950 and National Aeronautics and Space Administration (NASA) Johnson Space Center grant NAG 9-1115, and MP is supported by a grant from the Hungarian Science Fund (OTKA-T48607).

\section{References}

[1] D.A. Bazylinski, R.B. Frankel, Magnetosome formation in prokaryotes, Nat. Rev. Microbiol. 2 (2004) 217-230.

[2] S. Mann, Biomineralization: Principles and Concepts in Bioinorganic Materials Chemistry, Oxford University Press, Oxford, 2001

[3] M. Gajdardziska-Josifovska, R.G. McClean, M.A. Schofield, C. V. Sommer, W.F. Kean, Discovery of nanocrystalline botanical magnetite, Eur. J. Mineral. 13 (2001) 863-870.

[4] C. Zhang, H. Vali, C.S. Romanek, T.J. Phelps, S.V. Liu, Formation of single-domain magnetite by a thermophilic bacterium, Am. Mineral. 83 (1998) 1409-1418.

[5] R.G. McClean, M.A. Schofield, W.F. Kean, C.V. Sommer, D.P. Robertson, D. Toth, M. Gajdardziska-Josifovska, Botanical iron minerals: correlation between nanocrystal structure and modes of biological self-assembly, Eur. J. Mineral. 13 (2001) 1235-1242.

[6] X. Chatellier, D. Fortin, M.M. West, G.G. Leppard, F.G. Ferris, Effect of the presence of bacterial surfaces during the synthesis of Fe oxides by oxidation of ferrous ions, Eur. J. Mineral. 13 (2001) $705-714$

[7] J.F. Banfield, S.A. Welch, H. Zhang, T. Thomsen Ebert, R. Lee Penn, Aggregation-based crystal growth and microstructure development in natural iron oxyhydroxide biomineralization products, Science 289 (2000) 751-754.

[8] K.L. Thomas-Keprta, D.A. Bazylinski, J.L. Kirschvink, S.J. Clemett, D.S. McKay, S.J. Wentworth, H. Vali, E.K. Gibson Jr., C.S. Romanek, Elongated prismatic magnetite crystals in ALH84001 carbonate globules: potential Martian magnetofossils, Geochim. Cosmochim. Acta 64 (2000) 4049-4081.

[9] P.R. Buseck, R.E. Dunin-Borkowski, B. Devouard, R.B. Frankel, M.R. McCartney, P.A. Midgley, M. Posfai, M. Weyland, Magnetite morphology and life on Mars, Proc. Natl. Acad. Sci. U. S. A. 98 (2001) 13490-13495.

[10] J.F. Banfield, H. Zhang, Nanoparticles in the environment, in: J.F. Banfield, A. Navrotsky (Eds.), Nanoparticles and the Environment, Reviews in Mineralogy and Geochemistry, vol. 44, Mineralogical Society of America, Washington, DC, 2001, pp. $1-58$. 
[11] R.B. Frankel, D.A. Bazylinski, Biologically induced mineralization by bacteria, in: P.M. Dove, J.J. De Yoreo, S. Weiner (Eds.), Biomineralization, Reviews in Mineralogy and Geochemistry, vol. 54, Mineralogical Society of America, Washington, DC, 2003, pp. 95-114.

[12] T. Sakaguchi, J.G. Burgess, T. Matsunaga, Magnetite formation by a sulphate-reducing bacterium, Nature 365 (1993) 47-49.

[13] T. Sakaguchi, N. Tsujimura, T. Matsunaga, A novel method for isolation of magnetic bacteria without magnetic collection using magnetotaxis, J. Microbiol. Methods 26 (1996) 139-145.

[14] R. Kawaguchi, J.G. Burgess, T. Sakaguchi, H. Takeyama, R.H. Thornhill, T. Matsunaga, Phylogenetic analysis of a novel sulfate-reducing magnetic bacterium, RS-1, demonstrates its membership of the delta-Proteobacteria, FEMS Microbiol. Lett. 126 (1995) 277-282.

[15] T. Sakaguchi, A. Arakaki, T. Matsunaga, Desulfovibrio magneticus sp nov., a novel sulfate-reducing bacterium that produces intracellular single-domain-sized magnetite particles, Int. J. Syst. Evol. Microbiol. 52 (2002) 215-221.

[16] E.F. DeLong, R.B. Frankel, D.A. Bazylinski, Multiple evolutionary origins of magnetotaxis in bacteria, Science 259 (1993) 803-806.

[17] M. Farina, D.M.S. Esquivel, H.G.P. Lins de Barros, Magnetic iron-sulphur crystals from a magnetotactic microorganism, Nature 343 (1990) 256-258.

[18] S. Mann, N.H.C. Sparks, R.B. Frankel, D.A. Bazylinski, H.W. Jannasch, Biomineralization of ferrimagnetic greigite $\left(\mathrm{Fe}_{3} \mathrm{~S}_{4}\right)$ and iron pyrite $\left(\mathrm{FeS}_{2}\right)$ in a magnetotactic bacterium, Nature 343 (1990) 258-261.

[19] M. Pósfai, P.R. Buseck, D.A. Bazylinski, R.B. Frankel, Reaction sequence of iron sulfide minerals in bacteria and their use as biomarkers, Science 280 (1998) 880-883.

[20] M. Pósfai, P.R. Buseck, D.A. Bazylinski, R.B. Frankel, Iron sulfides from magnetotactic bacteria: structure, composition, and phase transitions, Am. Mineral. 83 (1998) 1469-1481.

[21] F. Widdel, F. Bak, Gram-negative mesophilic sulfate-reducing bacteria, in: A. Balows, H.G. Trüper, W. Dworkin, W. Harder, K.-H. Schleifer (Eds.), The Prokaryotes, Springer, Berlin, 1992, pp. 3352-3378.

[22] B.M. Moskowitz, R.B. Frankel, D.A. Bazylinski, Rock magnetic criteria for the detection of biogenic magnetite, Earth Planet. Sci. Lett. 120 (1993) 283-300.

[23] B. Carter-Stiglitz, B.M. Moskowitz, M. Jackson, More on the low-temperature magnetism of stable single domain magnetite: reversibility and non-stoichiometry, Geophys. Res. Lett. 31 (2004) L06606, doi:10.1029/2003GL019155.

[24] B. Devouard, M. Pósfai, H. Xin, D.A. Bazylinski, R.B. Frankel, P.R. Buseck, Magnetite from magnetotactic bacteria: size distributions and twinning, Am. Mineral. 83 (1998) $1387-1398$.

[25] B. Arató, Z. Szányi, C. Flies, D. Schüler, R.B Frankel, P.R. Buseck, M. Pósfai, Crystal-size and shape distributions of magnetite from uncultured magnetotactic bacteria as a potential biomarker, Am. Mineral. 90 (2005) 1233-1241.

[26] L. Tauxe, T.A.T. Mullender, T. Pick, Potbellies, wasp-waists, and superparamagnetism in magnetic hysteresis, J. Geophys. Res. 101 (1996) 571-583.

[27] D.J. Dunlop, Ö. Özdemir, Rock Magnetism: Fundamentals and Frontiers, Cambridge University Press, Cambridge, 1997.

[28] D.A. Bazylinski, B.M. Moskowitz, Microbial biomineralization of magnetic iron minerals, in: J.F. Banfield, K.H. Nealson (Eds.), Geomicrobiology: Interactions between Microbes and Minerals,
Reviews in Mineralogy, vol. 35, Mineralogical Society of America, Washington, DC, 1997, pp. 181-223.

[29] B. Carter-Stiglitz, M. Jackson, B. Moskowitz, Low-temperature remanence in stable single domain magnetite, Geophys. Res. Lett. 29 (2002), doi:10.1029/2001GL014197.

[30] B.P. Weiss, S.S. Kim, J.L. Kirschvink, R.E. Kopp, M. Sankaran, A. Kobayashi, A. Komeili, Ferromagnetic resonance and lowtemperature magnetic tests for biogenic magnetite, Earth Planet. Sci. Lett. 224 (2004) 73-89.

[31] Y. Pan, N. Petersen, M. Winklhofer, A.F. Davila, Q. Liu, T. Frederichs, M. Hanzlik, R. Zhu, Rock magnetic properties of uncultured magnetotactic bacteria, Earth Planet. Sci. Lett. 237 (2005) 311-325.

[32] Ö. Özdemir, D.J. Dunlop, B. Moskowitz, The effect of oxidation on the Verwey transition in magnetite, Geophys. Res. Lett. 20 (1993) 1671-1674.

[33] N. Guigue-Millot, N. Keller, P. Perritat, Evidence for the Verwey transition in highly nonstoichiometric nanometric Fe-based ferrites, Phys. Rev., B 64 (2001) 012402.

[34] R.B. Frankel, B. Moskowitz, Biological magnets, in: J.S. Miller, M. Drillon (Eds.), Magnetism: Molecules to Materials IV, WileyVCH, Weinheim, 2003, pp. 205-231.

[35] M. Evans, F. Heller, Environmental Magnetism: Principles and Applications of Enviromagnetics, Academic Press, Amsterdam, 2003.

[36] B.M. Moskowitz, R.B. Frankel, D.A. Bazylinski, H.W. Jannasch, D.R. Lovley, A comparison of magnetite particles produced anaerobically by magnetotactic and dissimilatory iron-reducing bacteria, Geophys. Res. Lett. 16 (1989) 665-668.

[37] M. Pósfai, K. Cziner, E. Márton, P. Márton, P.R. Buseck, R.B. Frankel, D.A. Bazylinski, Crystal-size distributions and possible biogenic origin of Fe sulfides, Eur. J. Mineral. 13 (2001) 691-703.

[38] R.E. Dunin-Borkowski, M.R. McCartney, R.B. Frankel, D.A. Bazylinski, M. Pósfai, P.R. Buseck, Magnetic microstructure of magnetotactic bacteria by electron holography, Science 282 (1998) 1868-1870.

[39] R.E. Dunin-Borkowski, M.R. McCartney, M. Posfai, R.B. Frankel, D.A. Bazylinski, P.R. Buseck, Off-axis electron holography of magnetotactic bacteria: magnetic microstructure of strains MV-1 and MS-1, Eur. J. Mineral. 13 (2001) 671-684.

[40] M.R. McCartney, U. Lins, M. Farina, P.R. Buseck, R.B. Frankel, Magnetic microstructure of bacterial magnetite by electron holography, Eur. J. Mineral. 13 (2001) 685-689.

[41] M. Vainshtein, N. Suzina, E. Kudryashova, E. Ariskina, New magnet-sensitive structures in bacterial and archaeal cells, Biol. Cell 94 (2002) 29-35.

[42] S. Glasauer, S. Langley, T. Beveridge, Intracellular iron minerals in a dissimilatory iron-reducing bacterium, Science 295 (2002) $117-119$.

[43] S. Mann, N.H.C. Sparks, R.P. Blakemore, Structure, morphology and crystal growth of anisotropic magnetite crystals in magnetotactic bacteria, Proc. R. Soc. Lond., B 231 (1987) $477-487$.

[44] R.H. Thornhill, J.G. Burgess, T. Sakaguchi, T. Matsunaga, A morphological classification of bacteria containing bullet-shaped magnetic particles, FEMS Microbiol. Lett. 115 (1994) 169-176.

[45] M. Hanzlik, M. Winklhofer, N. Petersen, Spatial arrangement of chains of magnetosomes in magnetotactic bacteria, Earth Planet. Sci. Lett. 145 (1996) 125-134.

[46] S. Weiner, P.M. Dove, An overview of biomineralization processes and the problem of the vital effect, in: P.M. Dove, 
J.J. De Yoreo, S. Weiner (Eds.), Biomineralization, Reviews in Mineralogy and Geochemistry, vol. 54, Mineralogical Society of America, Washington, DC, 2003, pp. 1-29.

[47] K.O. Konhauser, Diversity of bacterial iron mineralization, Earth-Sci. Rev. 43 (1998) 91-121.

[48] F.G. Ferris, K. Tazaki, W.S. Fyfe, Iron oxides in acid mine drainage environments and their association with bacteria, Chem. Geol. 74 (1989) 321-330.

[49] D.A. Brown, D.C. Kamineni, J.A. Sawicki, T.J. Beveridge, Minerals associated with biofilms occurring on exposed rock in a granitic underground research laboratory, Appl. Environ. Microbiol. 60 (1994) 3182-3191.

[50] C. Quintana, J.M. Cowley, C. Marhic, Electron nanodiffraction and high-resolution electron microscopy studies of the structure and composition of physiological and pathological ferritin, J. Struct. Biol. 147 (2004) 166-178.

[51] A. Sinha, J. Chakraborty, S.K. Das, S. Das, V. Rao, P. Ramachandrarao, Oriented arrays of nanocrystalline magnetite in polymer matrix produced by biomimetic synthesis, Mater. Trans. 42 (2001) 1672-1675.
[52] M. Nesterova, J. Moreau, J.F. Banfield, Model biomimetic studies of templated growth and assembly of nanocrystalline FeOOH, Geochim. Cosmochim. Acta 67 (2003) 1177-1187.

[53] O. Grassmann, R.B. Neder, A. Putnis, P. Löbmann, Biomimetic control of crystal assembly by growth in an organic hydrogel network, Am. Mineral. 88 (2003) 647-652.

[54] J.M. Combes, A. Manceau, G. Calas, Formation of ferric oxides from aqueous solutions: a polyhedral approach by X-ray absorption spectroscopy: II. Hematite formation from ferric gels, Geochim. Cosmochim. Acta 54 (1990) 1083-1091.

[55] U. Schwertmann, R.M. Cornell, Iron Oxides in the Laboratory: Preparation and Characterization, Wiley, Weinheim, 2000.

[56] D.E. Janney, J.M. Cowley, P.R. Buseck, Structure of synthetic 6line ferrihydrite by electron nanodiffraction, Am. Mineral. 86 (2001) 327-335.

[57] E. Rabani, D.R. Reichman, P.L. Geissler, L.E. Brus, Dryingmediated self-assembly of nanoparticles, Nature 426 (2003) 271-274. 